\title{
Association between sociodemographic characteristics of female community health volunteers and their knowledge and performance on maternal and child health services in rural Nepal
}

\author{
This article was published in the following Dove Press journal: \\ Journal of Multidisciplinary Healthcare \\ 21 March 2016 \\ Number of times this article has been viewed
}

\author{
Dilaram Acharya ${ }^{1,2}$ \\ Jitendra Kumar Singh ${ }^{3,4}$ \\ Samaj Adhikari ${ }^{5}$ \\ Varidmala Jain ${ }^{6}$ \\ 'Department of Community Medicine, \\ Kathmandu University, Devdaha \\ Medical College and Research \\ Institute, Devdaha-10, Rupandehi, \\ Nepal; ${ }^{2}$ Department of Public Health, \\ Purbanchal University, Sanjeevani \\ College of Medical Sciences, Butwal, \\ Rupandehi, Nepal; ${ }^{3}$ Department of \\ Community Medicine and Public \\ Health, Janaki Medical College, \\ Tribhuvan University, Janakpur, Nepal; \\ ${ }^{4}$ Department of Community Medicine, \\ Institute of Medical Sciences, Banaras \\ Hindu University, India; ${ }^{5}$ Institute \\ of Medicine, Maharajgunj Medical \\ Campus, Tribhuvan University, \\ Kathmandu, Nepal; ' ${ }^{6}$ Department \\ of Public Health, Faculty of Health \\ Sciences, Sam Higginbottom Institute \\ of Agriculture, Technology and \\ Sciences, Allahabad, India.
}

\begin{abstract}
Background: Engaging community health volunteers and community health workers to provide maternal and child health $(\mathrm{MCH})$ care services in resource-poor settings is one of the global and widely used concepts. Despite a great role of female community health volunteers (FCHVs) in MCH services in Nepal, few research studies have been performed in this area. Our research aimed to assess the knowledge and performance of FCHVs on $\mathrm{MCH}$ services associated with their sociodemographic characteristics.
\end{abstract}

Methods: A cross-sectional survey was conducted to assess the knowledge and performance on selected $\mathrm{MCH}$ services of FCHVs using structured questionnaire in 16 village development committees of Dhanusha district, Southern Terai, Nepal, from the first of January to the end of February of 2014. A total of 138 FCHVs were selected by using multistage random sampling technique. Logistic regression was employed to examine the association between selected sociodemographic characteristics and knowledge and performance on $\mathrm{MCH}$ services of FCHVs after adjusting for significant variables associated with knowledge and performance and within-cluster effect.

Results: Our findings demonstrated that sociodemographic characteristics were associated independently with good knowledge of FCHVs on MCH services: education level secondary and above (adjusted odds ratio [aOR] 5.2; 95\% confidence interval [CI] 2.2-12.2); residing in Mother and Infant Research Activities, nongovernmental organization working area (aOR 3.7; 95\% CI 1.5-8.8); and middle caste (aOR 3.3; 95\% CI 1.0-10.3). Similarly, satisfactory performance of FCHVs significantly associated with $\mathrm{MCH}$ services were education level secondary and above (aOR 8.9; 95\% CI 3.2-24.3) and residing in Mother and Infant Research Activities working areas (aOR 9.0; 95\% CI 3.5-22.6).

Conclusion: The study recommends considering education level while recruiting rural FCHVs and capacity enhancement through additional training and development programs in collaboration with developmental partner.

Keywords: FCHV, knowledge, performance, sociodemographic characteristics, Nepal

\section{Introduction}

The earliest concept of community health workers in the world came into existence from Chinese barefoot doctors program and Thailand village health volunteers and communicators. ${ }^{1,2}$ Community health volunteers and community health workers are potential assets to deal with many maternal and child health $(\mathrm{MCH})$ problems in resource-limited settings. Community health volunteers from Bangladesh demonstrated the good knowledge and
Correspondence: Dilaram Acharya Devdaha Medical College and Research Institute, Devdaha Municipality-10, Rupandehi, Nepal

Tel +9779857036390

Email dilaramacharyal23@gmail.com
Journal of Multidisciplinary Healthcare 20| 6:9 | | |-120

(c) (i) (5) 2016 Acharya et al. This work is published and licensed by Dove Medical Press Limited. The full terms of this license are available at https://www.dovepress.com/terms. cc) ${ }_{\mathrm{BY}} \mathrm{NC}$ php and incorporate the Creative Commons Attribution - Non Commercial (unported, v3.0) License (http://creativecommons.org/licenses/lby-nd/3.0/). By accessing the work you hereby accept the Terms. Non-commercial uses of the work are permitted without any further permission from Dove Medical Press Limited, provided the work is properly attributed. For

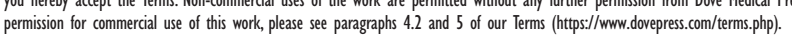


management of childhood illness. ${ }^{3-5}$ The concept of female community health volunteer (FCHV) program in Nepal was introduced in 1988-1989. ${ }^{6,7}$ Broadly, the chief goal of FCHV program is to help in achieving national health goal through community involvement. FCHVs, the self-motivated cadres selected by local mother's group, address MCH through promotional and preventive measures in conjunction with reducing child acute respiratory tract infections and diarrheal diseases and newborn care through curative measures. FCHVs are the major backbone in implementing public health programs, namely, family planning, safe motherhood, vitamin A supplementation, deworming, sick child care, and immunization. There are altogether 50,000 FCHVs in Nepal operating in each village development committee (VDC) under Family Health Division, Ministry of Health. ${ }^{6,8}$ The major health challenges of Nepal are life expectancy, infant, maternal, and under five mortality. High poverty, illiteracy, and geographical barrier are the key factors that affect the health status among Nepalese. ${ }^{9}$ In Nepal, according to Nepal Demographic and Health Survey, infant mortality rate is 45 per thousand and under five mortality rate is 54.5 per thousand. Similarly, maternal mortality ratio is 229 per hundred thousands live births and institutional delivery is $35.3 \% .^{10}$ There has been improvement in health indicators pertaining to $\mathrm{MCH}$, thanks to the active role of FCHVs. ${ }^{11}$

The major responsibilities of FCHVs delegated to them in delivering maternal health service delivery include counseling and advice during pregnancy, focusing on nutrition, antenatal care, immunization, iron and folate consumption, and postpartum visit. Similarly, in child health service delivery, they participate in delivering essential new born care (safe cord clamping, cord stump care, early breast feeding, and prevention of hypothermia), treating the child with acute respiratory tract infections, and early referral of the sick child. Assessing the knowledge and performance of health workers is essential; many countries focus on them as they are good assets for achieving the millennium development goals. ${ }^{12}$ Various sociodemographic correlates determine the level of knowledge and performance of community health workers. Community health workers of higher age group have better performance on service delivery. ${ }^{13}$ Female health workers of higher age group are established members of society and have already obtained enough exposures earlier. Educational level affects knowledge and performance of health workers. Literate workers are better owing to enhanced service delivery skills. Community health workers who have obtained higher level of education outperform those who are illiterate. ${ }^{14}$ Similarly, work experience as a health volunteer affects the level of knowledge and performance. Experienced ones outperform the naïve ones. ${ }^{15}$ Prior studies of Ethiopia and Nigeria, respectively, demonstrated work experience as a strong predictor of knowledge and practice toward tuberculosis control and injection safety among health workers. ${ }^{13,16}$

There is a synergistic effect of local nongovernmental organizations (NGOs) and performance of community health workers. In Nepal, Mother and Infant Research Activities (MIRA) is an NGO that conducts studies, launches interventions for improving maternal and infant health, and trains FCHVs. An effective program of neonatal sepsis identification and management with collaboration of local NGOs with community health volunteers has been reported in a previously published Nepalese article. ${ }^{17}$ An analytical report on national survey of FCHVs of Nepal reported that the highest percentage of FCHVs is in the age group 30-39 years. About $62 \%$ of FCHVs are literate, of which $42 \%$ have completed primary school or have ever gone to secondary education. Additionally, the same report highlighted that the FCHVs had better knowledge of MCH compared with rural women and performed better in terms of pregnancy counseling, and $>90 \%$ of them could provide essential newborn care. ${ }^{8}$ This study aims to highlight sociodemographic factors associated with knowledge and performance of FCHVs in delivering MCH services in rural Nepal.

\section{Materials and methods Study subjects and setting}

A cross-sectional survey assessing knowledge and performance of FCHV on $\mathrm{MCH}$ services using a structured questionnaire was used in 16 VDCs of Dhanusha district of Nepal from the first of January to the end of February of 2014. Among these 16 VDCs, six were engaged in MIRA, an NGO working in Dhanusha district, Nepal. The district was selected purposively because approximately all the indicators of $\mathrm{MCH}$ service utilization in this district were found lower as compared to adjacent district and national figure. ${ }^{6,17,18}$

\section{Study design and sampling}

This was a cross-sectional study conducted among 138 FCHVs working in 16 VDCs of Dhanusha district of Nepal. The sample size for this study was calculated by using a sample size calculator for finite population. ${ }^{19}$ There are 101 VDCs in Dhanusha district and 909 FCHVs working in rural area. Hence, the population size $(\mathrm{N})$ is $909 . P$ is taken as 0.12 (proportion of FCHVs in Dhanusha who miscategorized infant weight in a trial by MIRA is $12 \%) .{ }^{20}$ The permissible margin of error in the estimated value was taken as $5 \%$ with degree of assurance as 95\% confidence level. After entering all the values in the calculator, we obtained 134 FCHVs as the sample size. Taking all the FCHVs available during the survey in $16 \mathrm{VDCs}$, the total number of FCHVs included 
in this study became 138 as the final sample. Multistage random sampling was adopted to select FCHVs. Dhanusha district of Nepal was selected purposively. Out of seven primary health care centers (PHCCs) in Dhanusha district, four PHCCs were randomly selected. Then, the list of VDCs in the selected PHCCs was obtained from the District Public Health Office, Dhanusha. There were 35 VDCs in these four PHCCs. Altogether, 16 VDCs (four from each PHCC) were selected randomly to meet $138 \mathrm{FCHVs}$.

\section{Data management and statistical analysis}

A face-to-face interview was conducted using structured questionnaire. The outcome variables of the study were the knowledge and performance of FCHVs on $\mathrm{MCH}$ services. Assessment of knowledge and performance of FCHVs on $\mathrm{MCH}$ services was based on the several parameters of $\mathrm{MCH}$ services that are obtained from maternal and newborn health counseling package "Jeevan Suraksha" developed by United States Agency for International Development, which has been adopted by the Department of Health Services, Ministry of Health and Population, Government of Nepal, National Nutrition Policy and Strategy, and National FCHV Programme Revised Strategy of Nepal. ${ }^{21-23}$ Assessment of knowledge of FCHVs was assessed on the basis of the following ten major $\mathrm{MCH}$ parameters recommended by the Government of Nepal (see Supplementary Materials):

1. minimum number of antenatal care visit recommended;

2. total number of iron/folic acid tablets to be consumed during pregnancy;

3. dose for tetanus toxoid immunization;

4. dose of deworming;

5. presence of skilled birth attendants provides safe delivery;

6. number of postnatal visits recommended by the Government of Nepal;

7. number of iron tablets to be consumed postpartum;

8. dose of vitamin A;

9. number and time for child immunization; and

10. additional food intake required.

Assessment of performance of FCHVs was on the basis of the following ten parameters of $\mathrm{MCH}$ services recommended by the Government of Nepal:

1. create community awareness to promote health and healthy behaviors;

2. counsel pregnant women on antenatal visit and postnatal visit;

3. counsel pregnant women for safe delivery (skilled birth attendants/institutional delivery);

4. conduct regular mothers meeting;
5. counsel pregnant women for additional diet;

6. counsel postnatal mothers on breastfeeding, weaning, and growth monitoring;

7. distribute condom, pills, oral rehydration solution packets, and vitamin A capsules;

8. mobilize mother and children for immunization;

9. refer complicated cases to health institution; and 10. regular reporting of pregnancy to health facilities.

One score ( 0 or 1 ) was assigned for each parameter by asking the respondents for their knowledge and performance regarding $\mathrm{MCH}$ services. For knowledge, we assigned score 0 for each of the incorrect answer and score 1 for each of the correct answer. Similarly, a score was assigned for each of the parameter of performance. We assigned score 0 if there was no task performed by FCHVs and score 1 if there was partial or full task performed by FCHVs. As the score of these parameters ranged between 0 and 1 , the total possible maximum score is 10 for each knowledge and performance. The sum of scores for all the parameters for each participant was calculated and taken as the level of knowledge and performance. The median for knowledge and performance was calculated. The total scores for each respondent were then split in median. If the correct answers were equal or more than the median score, the FCHV's knowledge was considered "Good." If the correct answers were less than the median, the knowledge was considered "Poor." Similarly, performance was considered "Satisfactory" for equal and more than median scores and "Unsatisfactory" for scores less than the mean. ${ }^{24}$

Age of FCHVs was categorized as $<35$ years, 35-45 years, and $>45$ years. Education was recorded as literate/primary and secondary and above. Ethnicity/caste was based on the caste system in Nepal and was divided into three major groups based on available literature and similarities between the caste/ ethnic groups: advantaged/upper caste (Brahmin, Chhetri, and Bhumihaar), middle caste (Yadav, Koiri, Sudi/Teli), and lower caste (Dalit, Janjati, Mandal). ${ }^{25}$ Religion was categorized as Hindu and Muslims/others (Christian, Boudha). Working experience as a health volunteer was recorded as $<10$ years and $\geq 10$ years. Residential and working areas of FCHVs were categorized as MIRA and non-MIRA.

Knowledge in terms of good and poor category and performance in terms of satisfactory and unsatisfactory category were taken as the dependent variables. Age, education, caste, religion, work experience as a health volunteer, and place of residence at MIRA working area were taken as explanatory variables. The association between independent variables and the level of knowledge and performance were examined using chi-square $\left(\chi^{2}\right)$ test in univariate analysis. Then, the 
effect of each of the explanatory variables was adjusted for all other variables together in a multivariable logistic regression model. A $P$-value $\leq 0.05$ was considered statistically significant. Data were analyzed using Statistical Package for Social Sciences Version 20.0 for Windows.

\section{Ethics}

This study obtained the ethical approval from the Institutional Review Board of Banarus Hindu University, India, and written approval letter was obtained from District Health Office, Janakpur. The aims and objectives of the study were explained to the respondents before data collection. FCHVs provided written informed consent before an interview. Personal identifiers were removed before data analysis.

\section{Results}

\section{Differentials in characteristics of respondents' between known levels of knowledge and performances}

In a total of $138 \mathrm{FCHVs}$, three-quarters of them $(76.9 \%)$ were $>35$ years of age. Majority of them had more than secondary and above level of education (61.6\%), believed in the Hindu religion (79.0\%), work experience as volunteer $\geq 10$ years $(65.2 \%)$, and area of residence non-MIRA area $(62.3 \%)$. The unadjusted odds ratio shows that all the sociodemographic variables of the FCHVs were associated with good knowledge of $\mathrm{MCH}$ services except the religion. However, only the age, educational level, and area of residence where MIRA is working were associated with satisfactory level of performance on MCH care services (Table 1).

\section{Factors associated with knowledge and performance of $\mathrm{FCHVs}$ on maternal child health services}

The multiple logistic regression analysis was employed to analyze the factors associated with knowledge and performance of FCHVs on MCH services (Table 2). Adjusting for significant variables associated with knowledge and performance and within-cluster effect, level of education and area of residence where MIRA is working were significantly associated with both the knowledge and the performance of FCHVs. FCHVs who had education level secondary and above were likely to have good knowledge (adjusted odds ratio [aOR] 5.2; 95\% confidence interval [CI] 2.2-12.2) and satisfactory performance (aOR 8.9; 95\% CI 3.2-24.3) on MCH services than only literate and primary level of education. FCHVs who were residing in MIRA working areas were more likely to have good knowledge (aOR 3.7; 95\% CI 1.5-8.8) and satisfactory performance (aOR 9.0; 95\% CI 3.5-22.6) on MCH services than those who were residing beyond MIRA working areas.

Table I Knowledge and performance of FCHVs on MCH services according to sociodemographic characteristics

\begin{tabular}{|c|c|c|c|c|c|c|c|c|}
\hline \multirow[t]{2}{*}{ Characteristics } & \multicolumn{2}{|c|}{ Knowledge of FCHV } & \multirow{2}{*}{$\begin{array}{l}\text { OR } \\
(95 \% \mathrm{Cl})\end{array}$} & \multirow[t]{2}{*}{$P$-value } & \multicolumn{2}{|c|}{ Performance of FCHV } & \multirow{2}{*}{$\begin{array}{l}\text { OR } \\
(95 \% \mathrm{Cl})\end{array}$} & \multirow[t]{2}{*}{$P$-value } \\
\hline & $\begin{array}{l}\text { Poor } \\
(n=66, \%)\end{array}$ & $\begin{array}{l}\text { Good } \\
(n=72, \%)\end{array}$ & & & $\begin{array}{l}\text { Unsatisfactory } \\
(n=88, \%)\end{array}$ & $\begin{array}{l}\text { Satisfactory } \\
(n=50, \%)\end{array}$ & & \\
\hline \multicolumn{9}{|l|}{ Age (years) } \\
\hline$<35$ & $21(65.6)$ & II (34.4) & 1.00 & 0.048 & $27(84.4)$ & $5(15.6)$ & 1.00 & 0.002 \\
\hline $35-45$ & $26(38.8)$ & $4 \mid(6 \mid .2)$ & $3.0(1.2-7.2)$ & & $33(49.3)$ & $25(50.7)$ & $5.5(1.9-16.1)$ & \\
\hline$>45$ & 19 (48.7) & $20(5 \mid .3)$ & $2.0(0.7-5.2)$ & & $28(7 \mid .8)$ & $9(28.2)$ & $2.1(0.6-6.9)$ & \\
\hline \multicolumn{9}{|l|}{ Educational level } \\
\hline Literate/primary & $39(73.6)$ & $14(26.4)$ & 1.00 & $<0.001$ & 47 (88.7) & $6(11.3)$ & 1.00 & $<0.000$ \\
\hline Secondary and above & $27(31.8)$ & $58(68.2)$ & $5.9(2.7-12.8)$ & & $4 I(48.2)$ & $44(5 \mid .8)$ & $8.4(3.2-21.7)$ & \\
\hline \multicolumn{9}{|l|}{ Ethnicity/caste } \\
\hline Lower & $19(67.9)$ & $9(32.1)$ & 1.00 & 0.043 & $18(64.3)$ & $10(35.7)$ & 1.00 & 0.975 \\
\hline Middle & $29(46.8)$ & $33(53.2)$ & $2.4(0.9-6.1)$ & & $40(64.5)$ & $22(35.5)$ & $0.9(0.3-2.5)$ & \\
\hline Upper & $18(37.5)$ & $30(62.5)$ & $3.5(1.3-9.4)$ & & $30(62.5)$ & I8 (37.5) & $1.0(0.4-2.8)$ & \\
\hline \multicolumn{9}{|l|}{ Religion } \\
\hline Muslim/others & $17(58.6)$ & $12(4 \mid .4)$ & 1.00 & 0.193 & $19(65.5)$ & $10(34.5)$ & 1.00 & 0.826 \\
\hline Hindu & $49(45.0)$ & $60(55.0)$ & $1.7(0.7-3.9)$ & & $69(63.3)$ & $40(36.7)$ & I.I (0.4-2.6) & \\
\hline \multicolumn{9}{|l|}{ Work experience } \\
\hline$<10$ years & $33(68.8)$ & $15(3 \mid .2)$ & 1.00 & $<0.0001$ & $34(70.8)$ & $14(29.2)$ & 1.00 & 0.209 \\
\hline$\geq 10$ years & $33(36.7)$ & $57(63.3)$ & $3.8(1.8-8.0)$ & & $54(60.0)$ & $36(40.0)$ & $1.6(0.7-3.4)$ & \\
\hline \multicolumn{9}{|c|}{ Area of residence where MIRA working } \\
\hline No & $52(60.5)$ & $34(39.5)$ & 1.00 & $<0.0001$ & $67(77.9)$ & $19(22.1)$ & 1.00 & $<0.001$ \\
\hline Yes & $14(26.9)$ & $38(73.1)$ & $4.1(1.9-8.7)$ & & $21(40.4)$ & $31(59.6)$ & $5.2(2.4-11.0)$ & \\
\hline Total & $66(47.8)$ & $72(52.2)$ & & & $88(63.8)$ & $50(36.2)$ & & \\
\hline
\end{tabular}

Abbreviations: $\mathrm{FCHV}$, female community health volunteer; $\mathrm{MCH}$, maternal and child health; OR, odds ratio; Cl, confidence interval; MIRA, Mother and Infant Research Activities. 
Table 2 Multiple logistic regression model for knowledge and performance on $\mathrm{MCH}$ service of FCHVs

\begin{tabular}{|c|c|c|c|c|}
\hline Characteristics & $\begin{array}{l}\text { Knowledge (adequate/inadequate), } \\
\text { aOR }(95 \% \mathrm{Cl})\end{array}$ & $P$-value & $\begin{array}{l}\text { Performance (satisfactory/unsatisfactory), } \\
\text { aOR }(95 \% \mathrm{Cl})\end{array}$ & $P$-value \\
\hline \multicolumn{5}{|l|}{ Age (years) } \\
\hline$<35$ & 1.00 & 0.133 & 1.00 & 0.007 \\
\hline $35-45$ & $0.9(0.3-2.6)$ & & $5.4(1.3-20.8)$ & \\
\hline$>45$ & $0.3(0.1-1.1)$ & & I.2(0.2-5.I) & \\
\hline \multicolumn{5}{|l|}{ Educational level } \\
\hline Literate/primary & 1.00 & $<0.0001$ & 1.00 & 0.001 \\
\hline Secondary and above & $5.5(2.3-13.4)$ & & $6.6(2.2-19.9)$ & \\
\hline \multicolumn{5}{|l|}{ Caste/ethnicity } \\
\hline Lower & 1.00 & 0.053 & 1.00 & 0.456 \\
\hline Middle & $3.2(0.9-10.8)$ & & $1.4(0.2-3.7)$ & \\
\hline Upper & $2.5(0.7-8.8)$ & & $0.5(0.1-2.1)$ & \\
\hline \multicolumn{5}{|l|}{ Religion } \\
\hline Muslim/others & 1.00 & 0.586 & 1.00 & 0.981 \\
\hline Hindu & $1.3(0.4-3.9)$ & & $0.9(0.3-3.0)$ & \\
\hline \multicolumn{5}{|l|}{ Work experience } \\
\hline$<10$ years & 1.00 & 0.012 & 1.00 & 0.786 \\
\hline$\geq 10$ years & $3.1(1.2-7.5)$ & & $0.8(0.3-2.3)$ & \\
\hline \multicolumn{5}{|c|}{ Area of residence where MIRA working } \\
\hline No & 1.00 & 0.002 & 1.00 & $<0.0001$ \\
\hline Yes & $4.2(1.7-10.4)$ & & $8.3(3.1-22.5)$ & \\
\hline
\end{tabular}

Note: Variables entered: age group, literacy status, caste, religion, work experience, and place of residence in the working area of MIRA.

Abbreviations: $\mathrm{MCH}$, maternal and child health; $\mathrm{FCHV}$, female community health volunteer; aOR, adjusted odds ratio; Cl, confidence interval; MIRA, Mother and Infant Research Activities.

The result also revealed that middle caste FCHVs were more likely to have good knowledge (aOR 3.3; 95\% CI 1.0-10.3) on $\mathrm{MCH}$ services than upper and lower caste.

\section{Discussion}

Previously published research articles on FCHVs highlighted the detection and management of low-birth weight babies, early pregnancy detection, and use of FCHVs for childhood illness from user perspectives..$^{20,26,27}$ Our study demonstrated that knowledge and performance of FCHVs on $\mathrm{MCH}$ services are affected by selected sociodemographic factors in rural Nepal.

Increased level of education among FCHVs and their area of residence where MIRA is working are significantly associated with good knowledge and satisfactory performance on $\mathrm{MCH}$ services. FCHVs who had attained higher educational level were more likely to have sound knowledge and satisfactory performance, which could be attributed to contribution of school health curriculum and enhancement of service delivery skills with increasing educational level. Contrarily, a study done in India revealed that overqualified (with higher education) community health workers are less interested in field-based work and had lower performance level. ${ }^{28}$ However, this is consistent with one of the major findings of the Kenyan study that demonstrated that the higher level of education of community health workers was associated with better performance of maternal health services. ${ }^{14}$ Additionally, the finding in this study is similar with Nigerian and Bangladeshi studies..$^{29,30}$ MIRA, an NGO working for capacity improvement of FCHVs in Dhanusha district of Nepal, might influence the better knowledge and performance on $\mathrm{MCH}$ services. ${ }^{17}$ For the better performance of $\mathrm{MCH}$ service delivery in rural Nepal, therefore, more focus is needed on upgrading the level of education and engaging the development partners that can assist in improving FCHVs' knowledge and performance.

This study has strengths as it has identified some predictors on knowledge and performance of FCHVs on $\mathrm{MCH}$ services in rural Nepal based on primary data. However, this is not free from its limitations. As this cross-sectional study covered only a small area of Southern Terai, Nepal, the findings cannot be generalized to whole FCHVs existing in Nepal. Further study on FCHVs taking a large sample size and more variables is recommended.

\section{Conclusion}

Level of education and area of residence of FCHVs where an NGO is working influenced positively the knowledge and performance of $\mathrm{MCH}$ services. The study recommends considering level of education while recruiting rural FCHVs and capacity enhancement through additional training and development programs in collaboration with developmental partners. 


\section{Acknowledgments}

We would like to thank our research assistants and all FCHVs for their kind cooperation during this study. We are grateful to Deepak Adhikari, PhD (Department of Anatomy and Developmental Biology, Monash University, Melbourne, Victoria, Australia) for final English check and editing of our manuscript.

\section{Author contributions}

DA and JKS participated in the study design. DA and JKS performed statistical analysis and wrote manuscript with significant contribution from SA. SA and VJ contributed to the analysis, interpretation of the results, literature review, and revision of the manuscript. All the authors contributed in revision and agreed on the final manuscript.

\section{Disclosure}

The authors report no conflicts of interest in this work.

\section{References}

1. Kc N, Kc A, Sharma N, et al. Community participation and mobilization in community-based maternal, newborn and child health programmes in Nepal. J Nepal Health Res Counc. 2011;9(2):101-106.

2. Kawakatsu Y, Sugishita T, Kioko J, Ishimura A, Honda S. Factors influencing the performance of community health workers in Kisumu West, Kenya. Prim Health Care Res Dev. 2012;13(04):294-300.

3. Rashid SF, Hadi A, Afsana K, Begum SA. Acute respiratory infections in rural Bangladesh: cultural understandings, practices and the role of mothers and community health volunteers. Trop Med Int Health. 2001;6(4):249-255.

4. Hadi A. Management of acute respiratory infections by community health volunteers: experience of Bangladesh Rural Advancement Committee (BRAC). Bull World Health Organ. 2003;81(3):183-189.

5. Brown A, Malca R, Zumaran A, Miranda JJ. On the front line of primary health care: the profile of community health workers in rural Quechua communities in Peru. Hum Resour Health. 2006;4(1):11.

6. Department of Health Services. Annual report. Department of Health Services 2070/71 (2013/2014) Kathmandu: Department of Health Services, Ministry of Health and Population, Government of Nepal (GoN); 2014. Available from: http://dohs.gov.np/wp-content/uploads/2014/04/ Annual_Report_2070_71.pdf. Accessed February 18, 2016.

7. Glenton C, Scheel IB, Pradhan S, Lewin S, Hodgins S, Shrestha V. The FCHV programme in Nepal: decision makers' perceptions of volunteerism, payment and other incentives. Soc Sci Med. 2010;70(12): 1920-1927.

8. New ERA. An analytical report on national survey of female community health volunteers of Nepal. Kathmandu: United States Agency for International Development (USAID); 2007. Available from: https:// dhsprogram.com/pubs/pdf/FR181/FCHV_Nepal2007.pdf. Accessed February 18, 2016.

9. Deslich BJ. Health Issues in Nepal. 2003. Available from: http:// w3.whosea.org/drd/hlth_sit_nepal.htm. Accessed February 18, 2016.

10. Ministry of Health and Population. Nepal Demographic and Health Survey. Kathmandu: 2011. Available from: http://dhsprogram.com/ pubs/pdf/FR257/FR257\%5B13April2012\%5D.pdf Nepal and Calverton, Maryland, U.S.A.: Ministry of Health and Population, New ERA and ICF International; 2012. kathmandu: 2012. Accessed February 18, 2016.

11. Selemani M, Masanja IM, Kajungu D, et al. Health worker factors associated with prescribing of artemisinin combination therapy for uncomplicated malaria in rural Tanzania. Malar J. 2013;12(1):334.
12. Haines A, Sanders D, Lehmann U, et al. Achieving child survival goals: potential contribution of community health workers. Lancet. 2007:369(9579):2121-2131.

13. Gizaw GD, Alemu ZA, Kibret KT. Assessment of knowledge and practice of health workers towards tuberculosis infection control and associated factors in public health facilities of Addis Ababa, Ethiopia: a cross-sectional study. Arch Public Health. 2015;73(1):15.

14. Crispin N, Wamae A, Ndirangu M, et al. Effects of selected socio-demographic characteristics of community health workers on performance of home visits during pregnancy: a cross-sectional study in Busia District, Kenya. Glob J Health Sci. 2012;4(5):78.

15. Khiavi RF. Factors affecting the performance of health workers about family planning programs. WALIA J. 31(S1):175-179, 2015.

16. Onyemocho A, Anekoson JI, Pius EO. Knowledge and practice of injection safety among workers of Nigerian prison service health facilities in Kaduna state. Am J Public Health Res. 2013;1(7):171-176.

17. Shrestha BP, Bhandari B, Manandhar DS, Osrin D, Costello A, Saville N. Community interventions to reduce child mortality in Dhanusha, Nepal: study protocol for a cluster randomized controlled trial. Trials. 2011;12(1):136.

18. Department of Health Services. Annual Report. 2012/2013. Available from: http://dohs.gov.np/wp-content/uploads/2014/04/Annual_ Report_2069_70.pdf. Accessed February 18, 2016.

19. Kotrlik J, Higgins C. Organizational research: determining appropriate sample size in survey research appropriate sample size in survey research. Inform Tech Learn Perform J. 2001;19(1):43.

20. Amano S, Shrestha B, Chaube S, et al. Effectiveness of FCHVs in the detection and management of low-birth-weight in Nepal. Rural Remote Health. 2014;14(1):2508.

21. Department of Health Service, Population MoHa. National Nutrition Policy and strategy. Kathmandu: Ministry of Health and Population, Department of Health Services, Child Health Division, Nutrition Section; 2004. Available from http://dohs.gov.np/wpcontent/uploads/chd/Nutrition/ Nutrition_Policy_and_Strategy_2004.pdf. Accessed on March 3, 2016.

22. Department of Health Service, Population MoHa. National FCHV Program Revised Strategy. Kathmandu: Department of Health Service, Ministry of Health and Population. 2004. Available from http://www. mohp.gov.np/images/pdf/policy/FCHV\%20Strategy.pdf. Accessed March 03, 2016.

23. McPherson RA, Tamang J, Hodgins S, et al. Process evaluation of a community-based intervention promoting multiple maternal and neonatal care practices in rural Nepal. BMC Pregnancy Childbirth. 2010;10(1):31.

24. Khun M, Heng C, Kasuya H, Sakamoto J. Knowledge, attitudes and practices towards avian influenza A (H5N1) among Cambodian women: a cross-sectional study. Asian Pac J Trop Med. 2012;5(9): 727-734.

25. Khanal V, Adhikari M, Sauer K, Zhao Y. Factors associated with the introduction of prelacteal feeds in Nepal: findings from the Nepal demographic and health survey 2011. Int Breastfeed J. 2013;8(1):9.

26. Andersen K, Singh A, Shrestha MK, Shah M, Pearson E, Hessini L. Early pregnancy detection by FCHVs in Nepal facilitated referral for appropriate reproductive health services. Glob Health Sci Pract. 2013;1(3):372-381.

27. Miyaguchi M, Yasuoka J, Poudyal AK, Silwal RC, Jimba M. FCHVs service utilization for childhood illness- improving quality of health services only is not enough: a cross-sectional study in mid-western region, Nepal. BMC Health Serv Res. 2014;14:383.

28. Sharma R, Webster P, Bhattacharyya S. Factors affecting the performance of community health workers in India: a multi-stakeholder perspective. Glob Health Act. 2014;7:25352.

29. Ryan JM, John GC, Brieger WR. Five-year knowledge retention by volunteer primary health workers in western Nigeria. Int $Q$ Community Health Educ. 1990;11(2):123-133.

30. Ahmed SM, Hossain MA. Knowledge and practice of unqualified and semi-qualified allopathic providers in rural Bangladesh: implications for the HRH problem. Health Policy. 2007;84(2):332-343. 


\section{Supplementary materials}

\begin{tabular}{|c|c|}
\hline \multicolumn{2}{|c|}{$\begin{array}{c}\text { KNOWLEDGE AND PERFORMANCE OF FEMALE COMMUNITY HEALTH } \\
\text { VOLUNTEERS ON MCH SERVICES-2015 } \\
\text { SURVEY QUESTIONNAIRE IN DHANUSHA }\end{array}$} \\
\hline 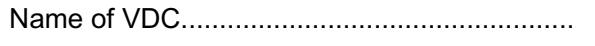 & \\
\hline 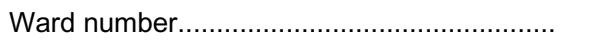 & \\
\hline Cluster name & \\
\hline 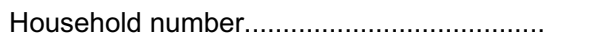 & \\
\hline 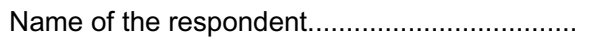 & \\
\hline $\begin{array}{l}\text { Date of visit } \\
(\mathrm{DD} / \mathrm{MM} / \mathrm{YY}) \ldots \ldots \ldots \ldots \ldots \ldots \ldots \ldots \ldots \ldots \ldots\end{array}$ & \\
\hline Interviewer's name & \\
\hline Result $^{\star} \ldots \ldots \ldots \ldots \ldots \ldots \ldots$ & \\
\hline
\end{tabular}

\section{RESULT CODES}

$1=$ Interview completed

$2=$ Respondent refused to be interviewed

$3=$ Respondent not at home

4= Other (specify).

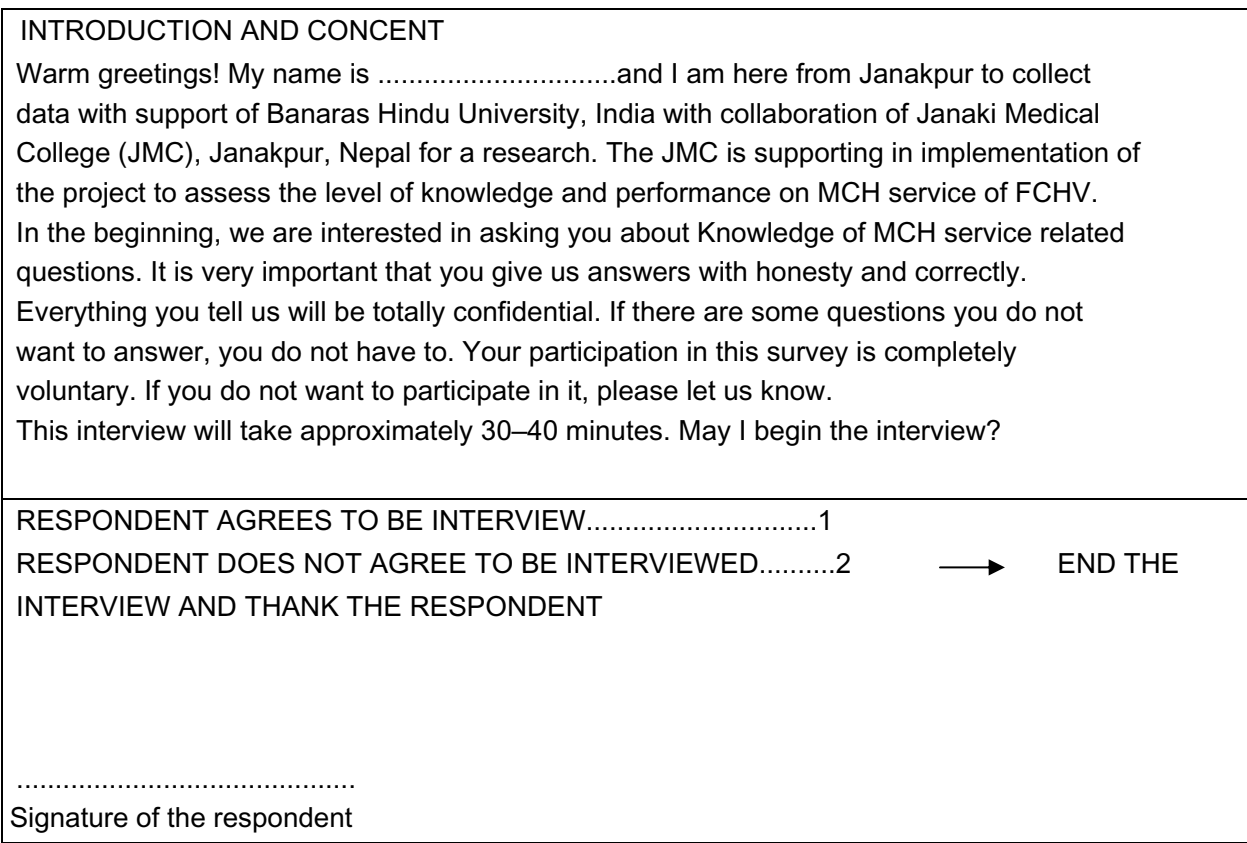

Figure SI Survey questionnaire.

Abbreviations: VDC, Village Development Committee; $\mathrm{MCH}$, maternal and child health; FCHV, female community health volunteer. 
Section-1: Socio Demographic Details-I

Interviewer: "Now I would like to ask some questions about you"

\begin{tabular}{|c|c|c|c|}
\hline $\begin{array}{l}Q \\
N\end{array}$ & Questions & Coding categories & Remarks \\
\hline 1. & How old are you? & Age in completed year.................. & \\
\hline 2. & $\begin{array}{l}\text { What is your } \\
\text { caste or } \\
\text { ethnicity? }\end{array}$ & $\begin{array}{ll}\text { 1. } & \square \text { Dalit Terai } \\
\text { 2. } & \square \text { Disadvantage Janajati Terai } \\
\text { 3. } & \square \text { Disadvantage non dalit tarai caste group } \\
\text { 4. } & \square \text { Religious minorities } \\
\text { 5. } & \square \text { Relatively advantaged Janajati } \\
\text { 6. } & \square \text { Upper caste group } \\
\end{array}$ & \\
\hline 3. & $\begin{array}{l}\text { What is your } \\
\text { religion? }\end{array}$ & $\begin{array}{l}\text { 1. } \quad \text { Hindu } \\
\text { 2. } \square \text { Muslim } \\
\text { 3. } \quad \square \text { Others....... }\end{array}$ & \\
\hline 4. & $\begin{array}{l}\text { What is the } \\
\text { highest education } \\
\text { level of...? }\end{array}$ & $\begin{array}{l}\text { 1. } \square \text { None } \\
\text { 2. } \square \text { Primary/informal education } \\
\text { 3. } \square \text { Lower secondary } \\
\text { 4. } \square \text { Secondary level } \\
\text { 5. } \square \text { Higher secondary } \\
\text { 6. } \square \text { Intermediate and above } \\
\end{array}$ & \\
\hline 5 & $\begin{array}{l}\text { For how many } \\
\text { years are you } \\
\text { working as } \\
\text { FCHV? }\end{array}$ & Experience in completed year............... & \\
\hline 6 & $\begin{array}{l}\text { Are you residence } \\
\text { of MIRA working } \\
\text { area? }\end{array}$ & $\begin{array}{l}\text { 1. } \square \text { Yes } \\
\text { 2. } \square \text { No }\end{array}$ & \\
\hline
\end{tabular}




\begin{tabular}{|c|c|c|c|c|c|}
\hline \multicolumn{6}{|c|}{ Section-2: Knowledge on MCH services } \\
\hline \multicolumn{6}{|c|}{$\begin{array}{l}\text { Interviewer: "Now I would like to ask some questions about your knowledge } \\
\text { on MCH services" }\end{array}$} \\
\hline \multirow[t]{2}{*}{ QN } & \multirow{2}{*}{$\begin{array}{l}\text { Questions } \\
\text { Please tell me regarding the following } \mathrm{MCH} \\
\text { services that should be taken by pregnant } \\
\text { and postpartum mothers? }\end{array}$} & \multicolumn{3}{|c|}{$\begin{array}{l}\text { Coding } \\
\text { categories }\end{array}$} & \multirow{2}{*}{$\begin{array}{c}\text { Go } \\
\text { to } \\
Q .\end{array}$} \\
\hline & & Yes & No & $D K$ & \\
\hline 11. & Minimum number of ANC visit recommended. & 0 & 1 & 8 & \\
\hline 12. & $\begin{array}{l}\text { Total number of IFA tablet to be consumed during } \\
\text { pregnancy. }\end{array}$ & 0 & 1 & 8 & \\
\hline 13. & Dose for TT immunization for pregnant & 0 & 1 & 8 & \\
\hline 14. & Dose of De-worming for pregnant & 0 & 1 & 8 & \\
\hline 15. & Is presence of SBA made delivery safe? & 0 & 1 & 8 & \\
\hline 16. & Number of Postnatal visit recommended by GoN & 0 & 1 & 8 & \\
\hline 17. & Number of Post partum Iron to be consumed. & 0 & 1 & 8 & \\
\hline 18. & Dose of Vitamin A & 0 & 1 & 8 & \\
\hline 19. & Number and time for Child Immunization & 0 & 1 & 8 & \\
\hline 20. & Additional food intake required. & 0 & 1 & 8 & \\
\hline
\end{tabular}


Section-3: Performance on MCH services

\begin{tabular}{|c|c|c|c|c|c|}
\hline \multirow[t]{2}{*}{ QN } & \multirow{2}{*}{$\begin{array}{l}\text { Questions } \\
\text { Please tell me regarding the } \\
\text { following } \mathrm{MCH} \text { services which you } \\
\text { performed in last } 6 \text { months for } \\
\text { pregnant and postpartum mothers? }\end{array}$} & \multicolumn{3}{|c|}{$\begin{array}{l}\text { Coding } \\
\text { categories }\end{array}$} & \multirow[t]{2}{*}{$\begin{array}{l}\text { Go } \\
\text { to } \\
Q .\end{array}$} \\
\hline & & Yes & No & $D K$ & \\
\hline 21. & $\begin{array}{l}\text { Create Community awareness to promote health and } \\
\text { healthy behaviors. }\end{array}$ & 0 & 1 & 8 & \\
\hline 22. & $\begin{array}{l}\text { Counsel pregnant women on antenatal visit and } \\
\text { postnatal visit. }\end{array}$ & 0 & 1 & 8 & \\
\hline 33. & $\begin{array}{l}\text { Counsel pregnant women for safe delivery (SBA/ } \\
\text { institutional delivery). }\end{array}$ & 0 & 1 & 8 & \\
\hline 24. & Conduct regular mothers meeting. & 0 & 1 & 8 & \\
\hline 25. & Counsel pregnant women for additional diet. & 0 & 1 & 8 & \\
\hline 26. & $\begin{array}{l}\text { Counsel postnatal mothers on breastfeeding, weaning } \\
\text { and growth monitoring. }\end{array}$ & 0 & 1 & 8 & \\
\hline 27. & $\begin{array}{l}\text { Distribute condom, pills, ORS packets, and Vitamin A } \\
\text { capsules. }\end{array}$ & 0 & 1 & 8 & \\
\hline 28. & Mobilize mother and children for immunization. & 0 & 1 & 8 & \\
\hline 29. & Refer complicated cases to health institution. & 0 & 1 & 8 & \\
\hline 30. & Regular reporting of pregnancy to health facilities. & 0 & 1 & 8 & \\
\hline
\end{tabular}

Abbreviations: MIRA, Mother and Infant Research Activities, IFA, iron and folic acid ; TT, tetanus toxoid; SBA, skilled birth attendants; GoN, Government of Nepal; ORS, oral rehydration salt; DK, do not know; ANC, antenatal care.

\section{Publish your work in this journal}

The Journal of Multidisciplinary Healthcare is an international, peerreviewed open-access journal that aims to represent and publish research in healthcare areas delivered by practitioners of different disciplines. This includes studies and reviews conducted by multidisciplinary teams as well as research which evaluates the results or conduct of such teams or health- care processes in general. The journal covers a wide range of areas and welcomes submissions from practitioners at all levels, from all over the world. The manuscript management system is completely online and includes a very quick and fair peer-review system. Visit http://www.dovepress.com/ testimonials.php to read real quotes from published authors. 